\title{
Overweight-obesity in children and adolescents aged 6 to 17, attending schools in school districts I and 2 in the region of greater moncton
}

\begin{abstract}
Introduction: Obesity and overweight are a public health problem not only in adults but also in children and adolescents.

Objectives: The purpose of this study is to assess the prevalence of overweight and obesity and its relationship with certain risk factors in children and adolescents aged 6 to 17 years in the region of Greater Moncton (Canada).

Methods: The size and weight of the subjects are collected through the general selfadministered questionnaire. BMI is extrapolated on growth curves based on the age of the CDC.

Results: $3.8 \%$ subjects fall into the category under weight, $80.6 \%$ in the category healthy weight, $10.3 \%$ in the category overweight, $5.3 \%$ in the category obesity and $15.6 \%$ in the combined category (overweight and obesity).

Conclusion: This study helped highlight that rates of obesity and overweight combined exceed not only the national rate but closer rates found among Aboriginal people living off-reserve.
\end{abstract}

Volume 7 Issue I - 2017

Arsenault Michelle, Slimane Belbraouet

École de Nutrition, Université de Moncton, Canada

Correspondence: Slimane Belbraouet, École de Nutrition, Université de Moncton, New Brunswick, Canada,

Email Slimane.belbraouet@umoncton.ca

Received: June 29, 2017 | Published: July 14, 2017

\section{Introduction}

Since a few decades, obesity is growing rapidly in Canada. This increase concern especially childhood obesity. ${ }^{1}$ Demographic and geographic factors are increasingly put forward in epidemiological studies $^{2}$ who defer differences in prevalence of obesity according to the communities and social groups. The geographical differences in the distribution by provinces in Canada is very marked; the highest rates tend to be observed in the provinces of the Atlantic. In 2004, in the Canadian Community Health Survey (CCHS), the combined rate of overweight and obesity of young people from 2 to 17years was significantly higher in New Brunswick (34\%) compared to the national average (26\%) and the prevalence of obesity was significantly higher in New Brunswick (13\%) than the national average (8\%). ${ }^{3}$ In addition, the study of the impact of language on the health is vitally important. According to Bowen, ${ }^{1}$ the language is the most indispensable dimension related to the health and could even explain the disparities often observed between the health of the general population and the persons in situation of minority. The purpose of this study is to assess the prevalence of overweight and obesity as well as some risk factors involved (weight, sex, age, language) in children and adolescents aged 6 to 17 of the Greater Moncton area.

\section{Subjects and methods}

\section{Population}

The subjects are young French or English speaking aged between 6 and 17 attending classes from the first to the twelfth year of schools in Districts 1 and 2 of the region of Greater Moncton (NB., Canada). The Greater Moncton region includes the cities of Moncton, Riverview and Dieppe. Over 300 subjects who agreed to participate in the study, 263 topics meet the established criteria were selected.

\section{Anthropometric measurements}

Size and weight of the subjects are collected through the general self-administered questionnaire. The size and weight will be used to calculate BMI. Subsequently, the BMI is extrapolated on BMI growth curves based on the age of the CDC. ${ }^{4}$

\section{Statistics}

The database is collected from the general questionnaire. Version 15.0 of SPSS software is used to perform the treatment of quantitative data with descriptive and multivariate analyses. The analyses were evaluated with $\mathrm{p}<0.05$ as significant level.

\section{Ethics approval}

The project was approved by the Ethics Committee of the research with human beings of the Université de Moncton (CER No. 0607028).

\section{Results and discussion}

\section{Weight categories}

Table 1 outlines sociodemographic data such as sex, age, and the language of schools attended. $3.8 \%$ subjects are into the category under weight, $80.6 \%$ in the category healthy weight and $15.6 \%$ in the combined category (overweight and obesity). These results are similar to data self-reported reported by Janssen et al., ${ }^{5}$ a study among Canadian youth aged 11 to $16 y$ ears. Another study by Souames et al. in 2005 on youth 11 to 17 showed $6.9 \%$ students are underweight, $75.4 \%$ had a normal weight, $8.9 \%$ are overweight and $8.7 \%$ are obese. On the other hand, results of our study are different with those reported Shields ${ }^{3}$ in CCHS showing that $18 \%$ of the subjects were overweight, $8 \%$ were obese and $26 \%$ were overweight or obese. 
Table I Sociodemographic data according to the different categories of weight

\begin{tabular}{|c|c|c|c|c|c|c|c|}
\hline & & $\begin{array}{l}\text { Subject } \\
\text { number } \mathbf{N}\end{array}$ & $\begin{array}{l}\text { Underweight } \\
\text { Percentile } \\
<5 \text { th }(\mathbf{N}) \%\end{array}$ & $\begin{array}{l}\text { Healthy weight } \\
\text { 5th } \leq \text { Percentile } \\
<85 \text { th }(\mathbf{N}) \%\end{array}$ & $\begin{array}{l}\text { Overweight } \\
\text { 85th } \leq \text { Percentile } \\
<\text { 95th (N)\% }\end{array}$ & $\begin{array}{l}\text { Obesity } \\
\text { Percentile } \geq 95 \text { th } \\
\text { (N)\% }\end{array}$ & $\begin{array}{l}\text { Combined } \\
\text { Overweight- } \\
\text { Obesity (N)\% }\end{array}$ \\
\hline \multicolumn{8}{|c|}{ Sujets per } \\
\hline \multicolumn{8}{|l|}{ Category } \\
\hline \multirow{7}{*}{ Gender } & Boys & 97 & (5) 5.1 & (73) 75.4 & (II) II.4 & (8) 8.1 & 19.5 \\
\hline & Girls & 166 & (5) 3.0 & 83.8 (139) & 9.6 & (6) 3.6 & (22) 13.2 \\
\hline & 6 & 3 & (0) 0.0 & (2) 66.7 & (I) 33.4 & (0) 0.0 & (I) 33.4 \\
\hline & 7 & 5 & (0) 0.0 & (3) 57.9 & (2) 42.1 & (0) 0.0 & (2) 42.1 \\
\hline & 8 & 10 & (2) $2 \mathrm{I} . \mathrm{I}$ & (4) 39.5 & (3) 28.9 & (I) 10.5 & (4) 39.4 \\
\hline & 9 & 12 & (I) 8.5 & (7) 57.5 & (2) 17.0 & (2) 17.0 & (4) 34.0 \\
\hline & II & 49 & (2) 4.3 & (40) 81.7 & (4) 8.1 & (3) 5.9 & (7) 14 \\
\hline \multirow[t]{7}{*}{ Age } & 12 & 61 & (3) 5.1 & (48) 78.5 & (6) 9.9 & (4) 6.5 & (I0) 16.4 \\
\hline & 13 & 30 & (0) 0.0 & (26) 86.8 & (4) 13.2 & (0) 0.0 & (4) 13.2 \\
\hline & 14 & 23 & (0) 0.0 & (22) 95.4 & (I) 4.6 & (0) 0.0 & (I) 4.6 \\
\hline & 15 & 19 & (0) 0.0 & (I8) 94.4 & (I) 5.6 & (0) 0.0 & (I) 5.6 \\
\hline & 16 & 19 & (0) 0.0 & 83.6 & (I) 5.5 & (2) 10.9 & (3) 16.4 \\
\hline & 17 & 14 & (I) 7.4 & (I2) 85.2 & (I) 7.4 & (0) 0.0 & (I) 7.4 \\
\hline & 18 & 8 & (I) 12.9 & (5) 61.3 & (I) 12.3 & (I) 12.9 & (2) 25.2 \\
\hline $\begin{array}{l}\text { School } \\
\text { districts }\end{array}$ & $\begin{array}{l}\text { I (French } \\
\text { speaking) }\end{array}$ & 190 & (7) 3.7 & (I55) 81.6 & 10.0 & (9) 4.7 & (28) I4.7 \\
\hline
\end{tabular}

\section{Gender}

In the study presents, a greater percentage of boys than girls is part of the category under weight $(5.1 \%$ vs $3.0 \%)$ overweight $(11.4 \%$ vs $9.6 \%)$, obesity ( $8.1 \%$ vs. $3.6 \%$ ) and overweight/obesity combined $(19.5 \%$ vs. $13.2 \%)$. In addition, many more girls in the healthy weight category $(83.8 \%$ vs $75.4 \%)$. This same information is reported by Receveur et al. (2008), who observe no significant difference between the different sexes according to the distribution of the subjects in the weight categories. Also, Shields ${ }^{3}$ notes that the increase in the prevalence of overweight and obesity is similar for boys and girls. According to Brunet et al., ${ }^{6}$ a study in subjects Quebecers aged 7, 8 and 10 , the percentage of girls who was part of the weight of overweight category was larger than the percentage found among boys.

\section{Age}

$70 \%$ of the population studied is in the age group of 10 to 15 years. These participation rates are also observed in the CCHS that shows variation according to different age groups. The highest rate of participation is found in the age group of 12 to 17 years $(71 \%)$ and the lowest in the 6 to 11 age group $(66 \%){ }^{3}$

\section{Overweight/Obesity}

The percentages of subjects aged 6, 7, 8, and 9years in these categories of weight are respectively $33.4,42.1,39.4$, and $34 \%$.
These percentages rather resemble the average overweight and obesity combined in New Brunswick (34\%), which is significantly higher than the national average $(26 \%){ }^{3}$ Even more worrisome is that the average age of 7 and 8years who belong to the category of combined overweight/obesity (42.1 and $39.4 \%$ respectively), is close to the average for the same category of weight, found among young Aboriginal Canadians living off-reserve, which is $41 \%$, such as described by Shields. ${ }^{3}$ However, the subjects aged between 10 to 17 years show a low percentage of combined overweight and obesity, $10.5,14.0,16.4,13.2,4.6,5.6,16.1$ and $7.4 \%$, such as found by Shields ${ }^{3}$ in young people from Asia and Southeast Asia (18\%). On the other hand, the spoken language (French or English) does not seem to have a significant effect on the prevalence of overweight or obesity. 7,8

\section{Conclusion}

Due to the small number of subjects in each age category, it is very difficult to draw statistical conclusions. However, we can observe interesting trends such the average obesity of 9year old, rates close to the data in young Aboriginal Canadians living off-reserve. When we consider the combined overweight/obesity weight category, the same image recurs. Percentages of the subjects aged between 6-9years in this category are compared to the overweight/obesity combined in New Brunswick, which is substantially higher than the national average. A fact even more worrisome is that the average combined overweight/obesity weight category of 7 and 8years is close to the 
average found among young Aboriginal Canadians living off-reserve. On the other hand, the subjects aged between 10 to 17 years showed a low percentage of overweight/obesity combined, close to the percentages found in young people from Southeast Asia and East Asia.

\section{Acknowledgements}

None.

\section{Conflict of interest}

The author declares no conflict of interest.

\section{References}

1. Bowen S, Gibbens M, Roy J, et al. From 'multicultural health' to 'knowledge translation' rethinking strategies to promote language access within a risk management framework. Journal of Specialised Translation. 2010;14:145-164.

2. O'Loughlin J, Paradis G, Meshefedjian G, et al. Clustering of lifestyle risk factors for chronic disease by family origin among children in lowincome, multiethnic urban neighbourhoods in Montreal. Ethnicity and Disease. 2004;14:340-350.
3. Shields M. Nutrition: Résultats de l'Enquête sur la santé dans les collectivités Canadiennes; Obésité mesurée; L'embonpoint chez les enfants et les adolescents au Canada. Statistique Canada no 82-620MWF. 2005.

4. Courbes de croissances des CDC américains. National Center for Chronic Disease Prevention and Health Promotion. 2000.

5. Janssen I, Katzmarzyk PT, Boyce WF, et al. Overweight and obesity in Canadian Adolescents and their Associations with Dietary Habits and Physical Activity Patterns. J Adolesc Health. 2004;35(5):360-367.

6. Brune M, Chaput JP, Tremblay A. The association between low physical fitness and high body mass index or waist circumference is increasing with age in children: the 'Québec en Forme' Project. Int $J$ Obes. 2007;31(14):637-643.

7. Receveur O, Karimou M, Gray-Donald K, et al. French fries and potato chips are associated with excess weight among elementary schoolage children in a Canadian First Nations Community. Journal of the American Dietetic Association. 2008;108:362-366.

8. Souames M, Brun P, Losfeld P. Surpoids et régime alimentaire chez l'adolescent:étude dans les collèges du département des Hauts-de-Seine. Pédiatrie au quotidien. 2005;12:1540-1543. 